\title{
Associations between Nutrition Knowledge, Vitamin C Intake, Nutritional Status, and Blood Pressure among Elderly with Hypertension in Klaten, Central Java, Indonesia
}

\author{
Triagung Yuliyana, ${ }^{1}$ Kusnandar, $^{2}$ Diffah Hanim ${ }^{3}$ \\ ${ }^{1}$ Master Program in Human Nutrition, Sebelas Maret University \\ ${ }^{2}$ Departement of Agribusiness Science Program, Sebelas Maret University \\ ${ }^{3}$ Departement of Nutrition Health Science Program, Sebelas Maret University
}

\begin{abstract}
Objective: To analyze the correlation between nutrition knowledge, vitamin $\mathrm{C}$ intake, and nutritional status on blood pressure among elderly with hypertension.

Methods: This was a cross-sectional study with purposive random sampling which was conducted from April to May 2017. This study included one hundred twenty-five elderly subjects with hypertension who met the inclusion criteria (17 males and 108 females), aged $\geq 60$ years, who lived in the work area of Juwiring Public Health Center in Klaten district, Central Java, Indonesia. The data were analyzed statistically by using normality, correlation, and multiple linear regression tests.

Results: The results of the correlation test showed that there was a correlation between nutrition knowledge $(p=0.011)$, vitamin $C$ intake $(p=0.012)$, nutritional status $(\mathrm{p}=0.048)$, and blood pressure hypertension in elderly based on the results of multiple linear regression. All data were analyzed statistically using Spearman correlation test to examine the distributed data. A significant correlation was found between nutrition knowledge, vitamin $\mathrm{C}$ intake, and nutritional status $(\mathrm{p}<0.05)$ using multiple linear regression $(p<0.05)$. A normality test using the Kolmogorov-Smirnov test resulted in normal residue with p-value 0.000 . The results showed that the regression analysis could be used to predict the blood pressure.
\end{abstract}

Conclusions: There was a correlation between nutrition knowledge and blood pressure of hypertension in elderly. There was a correlation between

Received:

September 20, 2017 vitamin $\mathrm{C}$ intake and a blood pressure of hypertension in elderly. There was a

Revised:

October 27, 2017 Keywords: Blood pressure, elderly hypertension, nutrition knowledge,

Accepted:

February 20, 2017 pISSN: 2302-1381; eISSN: 2338-4506; http://doi.org/10.15850/ijihs.v6n1.1114

IJIHS. 2018;6(1):22-9

\section{Introduction}

Data from World Health Organization (WHO) in 2013 stated that high blood pressure is one of the most important risk factors for cardiovascular disease (CVD), contributing to

\footnotetext{
Correspondence:

Triagung Yuliyana, Masters Program in Human

Nutrition, Sebelas Maret University

Jl. Danau Sentani Utara VIII Block H3/H8, Sawojajar,

Malang, Indonesia

e-mail: yanacool44@gmail.com
}

half of the prevalent coronary heart disease and approximately two-thirds of the prevalent cerebrovascular disease burdens, the leading cause of mortality among Indonesian elderly. The Indonesian population is aging and it is projected that the number of Indonesian adults $\geq 60$ years of age will be doubled by $2020 .{ }^{1}$ The incidence and prevalence of noncommunicable diseases (NCDs), including hypertension, increase with age. Therefore, the impact of high blood pressure among 
older adults on morbidity and mortality is expected to grow over the coming decades. The Joint National Committee (JNC-7) recently recommended a higher systolic blood pressure (SBP) threshold $(\geq 160 \mathrm{mmHg})$ for adults $\geq 60$ years of age without diabetes or chronic kidney disease. ${ }^{2}$

Almost forty-one million elderly people do not know what to do to control their blood pressure. Among the several reasons for this situation lack of knowledge and control of hypertension might be potentially included. ${ }^{3}$

Elderly nutrition problems increases due to various factors such as lack of knowledge on elderly nutrition and good food processing for the elderly which then directly affects the status of elderly nutrition. Psychological influence, dietary errors, and low economic status of the families may also lead to inadequate nutrition among elderly. ${ }^{4}$ Elderly are characterized by their unique conditions as a result of physiological changes which are characteristics of aging, as well as diseases and psychosocial and dietary factors that influence their nutritional status. ${ }^{5}$

In general, elderly experiences increased risk of malnutrition caused by insufficient food intake (amount) and poor selection of food (quality). This situation is aggravated when they are institutionalized. A study has shown that the occurrence of nutritional disorders in institutionalized elderly ranges from $30 \%$ to $80 \%$ with negative health consequences. ${ }^{6}$ Any deficiency, such as nutrient deficiency can compromise the health of the elderly, leading to loss of muscle mass, poor wound healing, depression, reduced memory and dementia, situations which are aggravated by the presence of malnutrition. In contrast, inadequate consumption of calories and lipids can contribute to a higher occurrence of excess weight, a condition that is also prevalent in this group, as well as cardiovascular diseases, neoplasms, and other disorders. ${ }^{5}$

A significant body of epidemiological and clinical trial data suggest that diets that are known to contain significant concentration of naturally occurring antioxidants appear to reduce blood pressure and may reduce the risk for cardiovascular diseases. ${ }^{2}$

Vitamin C (ascorbic acid) is an essential micronutrient required for normal metabolic functioning of the body. Human and other primates have lost the ability to synthesize vitamin $\mathrm{C}$ as a result of a mutation in the gene coding for L-gulonolactone oxidase, an enzyme required for the biosynthesis of vitamin $C$ via the glucuronic acid pathway. Thus, vitamin
C must be obtained through the diet. The vitamin is especially plentiful in fresh fruit, in particular citrus fruit, as well as vegetables, supplements, fortified beverages, and fortified breakfast or "ready to eat" cereals. ${ }^{7}$

Vitamin $C$ is known as a powerful aqueous phase antioxidant that can reduce oxidative stress and enhance endothelial function by way of its effects on nitric oxide production. Antihypertensive effects of vitamin $\mathrm{C}$ has been hypothesized as early as $1946 .{ }^{8}$ Consumption of fruit and vegetables has a particularly strong association with lower levels of blood pressure and a lower risk of hypertension. Intake of vitamin $\mathrm{C}$ derived from plants has also been shown to be associated with lower levels of blood pressure. Inadequate food intake may cause vitamin $\mathrm{C}$ concentrations to decrease. Vitamin C has important biological functions, including an increase in nitric oxide endothelial bioactivity. ${ }^{7}$ The intraarterial administration of ascorbic acid is reported to reverse impaired endothelium-dependent vasodilation found in various conditions associated with increased cardiovascular risk. A randomized, doubleblind, placebo-controlled study was conducted to investigate the hypothesis that chronic supplementation of oral ascorbic acid may help to reduce systemic arterial stiffness. ${ }^{9}$

This study aimed to observe the correlation between knowledge on nutrition, vitamin $\mathrm{C}$ intake, nutritional status, and blood pressure among elderly with hypertension.

\section{Methods}

This was a cross-sectional descriptive study performed in Juwiring Public Health Center, Klaten district, Central Java, Indonesia during a period of April to May 2017. This study has received an ethical approval from the Ethical Committee of Dr. Moewardi Public General Hospital with the issuance of Ethical Clearance no 468/V/HREC/2017.

Total sampling approach was applied for data collection using the purposive random sampling technique with a sample size of 361 elderly based on the result of the calculation using the sample size formula for descriptive study. Only 125 elderly with hypertension met the inclusion criteria: (1) elderly having id card, (2) age $\geq 60$ years old, (3) blood pressure $>140 \mathrm{mmHg}$, (4) male and female, (5) be able to hear, see, read, write, and communicate well. The exclusion criteria used in this study were (1) elderly with chronic kidney disease (CKD), diabetes mellitus (DM) and stroke, (2) 
moving home during the period of the study, (3) consumption antihypertensive drugs.

Face-to-face interview technique was used based on several questionnaires administered by the author. Data on nutrition knowledge were collected through twelve questions that has been validated by way of a nonparametric correlation instrument. The confidentiality of personal information was assured during the interview. Instrument used for data collection on vitamin C intake was performed using Food Frequency Questionnaire (FFQ) as well as the $2 \times 24$ hour food recall form. Blood pressure was measured one time during the study. Body weight and height were also measeured during the interview.

Uncontrolled hypertension is indicated with a systolic blood pressure (SBP) of $>140$ $\mathrm{mm} \mathrm{Hg}$ and diastolic blood pressure (DBP) of $>90 \mathrm{~mm} \mathrm{Hg}$ based on the standard used by the Seven Joint National Committee (JNC-7). The body mass index (BMI) as a ratio of weight (kg) to height $\left(\mathrm{m}^{2}\right)$ was also measured in this study. Patients were considered obese if the BMI was $>30 \mathrm{~kg} / \mathrm{m}^{2}$, which was based on the WHO criteria.

Table 1 Data Characteristics

\begin{tabular}{|c|c|c|c|}
\hline Subject Characteristics & Average \pm SD & $\begin{array}{c}\text { Median } \\
\text { (Min-Max) }\end{array}$ & $\mathbf{n}$ \\
\hline \multicolumn{4}{|l|}{ Sex } \\
\hline Male & & & 17 \\
\hline Female & & & 108 \\
\hline \multicolumn{4}{|l|}{ Blood Pressure (mmHg) } \\
\hline Systole & $162.10 \pm 16.98$ & $80(140-220)$ & 125 \\
\hline Diastole & $90.58 \pm 10.43$ & $30(90-120)$ & \\
\hline Age (years) & $68.46 \pm 6.66$ & $30(60-90)$ & 125 \\
\hline Body weight (kg) & $52.66 \pm 11.34$ & $73(32-105)$ & 125 \\
\hline Body height (cm) & $151.86 \pm 6.710$ & $34(136-170)$ & 125 \\
\hline BMI $\left(\mathrm{kg} / \mathrm{m}^{2}\right)$ & $22.71 \pm .39 .18$ & $21(15-36)$ & 125 \\
\hline Nutrition knowledge & $7.89 \pm 2.541$ & $11(1-12)$ & 125 \\
\hline \multicolumn{4}{|l|}{ Level of education } \\
\hline Not Attend School & & & 39 \\
\hline Elementary School & & & 67 \\
\hline Middle School & $0.94 \pm 0.905$ & $4(0-4)$ & 11 \\
\hline High School & & & 4 \\
\hline University & & & 4 \\
\hline \multicolumn{4}{|l|}{ Nutrient intake } \\
\hline Energy (Calorie/day) & $1122.72 \pm 523.32$ & $1573.8(367.45-1941.3)$ & 125 \\
\hline Protein (g/day) & $25.31 \pm 9.58$ & $50.2(9.15-59.35)$ & 125 \\
\hline Fat (g/day) & $25.10 \pm 10.47$ & $51.96(6.6-58.55)$ & 125 \\
\hline Carbohydrate (g/day) & $116.19 \pm 45.99$ & 235.15 (50-285.15) & 125 \\
\hline Vitamin C (mg/day) & $41.44 \pm 55.20$ & $508(1-509)$ & 125 \\
\hline
\end{tabular}

Note: BMI= body mass index

*normally distributed data using normality Kolmogorov-Smirnov test 
Table 2 Pearson Correlation Test between Nutrition Knowledge, Vitamin C Intake, Nutritional Status, and Elderly Hypertension

\begin{tabular}{|c|c|c|c|}
\hline $\begin{array}{l}\text { Elderly hypertension } \\
\text { (n=125) }\end{array}$ & $\begin{array}{c}\text { Nutrition } \\
\text { Knowledge }\end{array}$ & $\begin{array}{c}\text { Vitamin C Intake } \\
\text { (mg/day) }\end{array}$ & $\begin{array}{c}\text { Nutritional Status } \\
\left(\mathrm{kg} / \mathrm{m}^{2}\right)\end{array}$ \\
\hline Correlation coefficient (r) & -0.471 & 0.410 & 0.323 \\
\hline $\mathrm{p}$ value & 0.002 & 0.025 & 0.039 \\
\hline
\end{tabular}

${ }^{*}$ p value $<0.05$

Statistical tests were used to determine the relationship between nutrition knowledge, vitamin C intake, nutritional status, and blood pressure. The statistical tests used in this study were normality test descriptive statistics, Pearson correlation based on data distribution, and multiple regression test.

\section{Results}

The general characteristics of the elderly are presented in details (Table 1). One hundred twenty-five participants were initially invited to participate in this study but only 17 males and 108 males, the number of a female was higher than the male participants (Table 1). Most of the patients were in the age range of 60-90 years old. Based on the level of education, most participants were elementary school graduates.

In this study, the results from the blood pressure measurement was then classified according to JNC-7 standard into degree 1 (systolic pressure of 140-159 $\mathrm{mmHg}$ ) and degree 2 (systolic pressure of $\geq 160 \mathrm{mmHg}$ ). It turned out that the number of participants with degree 1 blood pressure was higher than those in degree 2.

Analysis was then performed to explore the correlation between nutrition knowledge, vitamin C intake, and nutritional status (Table 2 and 3). The results showed the presence of correlations between the nutrition knowledge $(p=0.002)$, vitamin $C$ intake $(p=0.025)$, and also nutritional status $(\mathrm{p}=0.039)$ in elderly hypertension (Table 2). These correlations were also found to be statistically significant for nutrition knowledge $(\mathrm{p}=0.011)$, vitamin $C$ intake $(p=0.012)$ and nutritional status $(p=0.048)$ (Table 3). Sex, age and level of education were the main variables influencing results and are shown to have a correlation with blood pressure in elderly hypertension. However, this correlation was not statistically significant. Regression analysis was repeatedly done for the independent variables in the study, such as sex, age and level of education.

The residual descriptive statistical test was performed by analyzing residual distribution using the Kolmogorov-Smirnov test. Here, the residual distribution was defined by normal distribution with a mean $=0$ ( $t$ test) while the $t$ value for the blood pressure in the current study was found to be 0.404 with $p>0.05$ and mean $=0$. The residual distribution results were: nutrition knowledge $=0.515$, vitamin $C$ intake $=0.375$ and nutritional status $=0.404$. This showed that the residual distribution was based on a normal distribution with mean $=0$.

\section{Discussion}

Most elderly participating in this study had good nutrition knowledge (Table 1). Results of the multivariate analysis indicate that there is a significant influence of nutrition knowledge on high blood pressure after the confounding variables were controlled (Table 3 ). Only two questions in the twelve-question nutrition knowledge questionnaire that received correct answers from less than $50 \%$ participants. The first question was regarding potassium intake through banana to reduce hypertension and the second question was about grains and nuts as the source of vitamin E.

The nutrition knowledge was good because most participants answered correctly for more than $50 \%$ of the questions (10 questions). From the observation it was revealed that most elderly in this study was classified to have degree 1 blood pressure (78 of 125) that it can be concluded that the better the 
nutrition knowledge, the lower the degree of hypertension is in elderly.

With better knowledge, it is expected that the blood pressure can be modified towards normal. This is in accordance with the notion that the level of one's health can be determined by the level of knowledge of the person; hence, the better the level of one's knowledge, the better the health level that person is. ${ }^{10}$ Information/knowledge about nutrition was obtained through various sources. Educational level, communication, information received, culture, and personal experience will affect the knowledge on health.

Appropriate information on hypertension provided to the elderly will give sufficient knowledge and will enable them to adopt healthy lifestyle as well as reducing the risk for degenerative diseases, especially hypertension and cardiovascular disease. ${ }^{3}$ The results of this study is in line with those of a previous study stating significant relationship between knowledge and blood pressure significantly $(p=0.016)$ and controlled blood pressure $(\mathrm{p}=0.032)^{4,10}$

There are several ways to obtain knowledge, including trial and error, will power, personal experience, and thinking. Information is one way to gain knowledge. Correct information on hypertension received by elderly will provide sufficient knowledge to be able to implement healthy lifestyle. ${ }^{10}$ The level of knowledge on hypertension is related to patient's compliance to hypertension treatment and adherence to hypertension diet. ${ }^{11}$ The implementation of a healthy lifestyle and appropriate treatment will be able to reduce the risk for hypertension and cardiovascular diseases. ${ }^{4} \mathrm{~A}$ survey in the USA among people older than 65 years found a similar knowledge level regarding lifestyle factors that may influence blood pressure but with higher knowledge level on the prevalence of knowledge on complications of untreated high blood pressure. ${ }^{12}$

Awareness on hypertension increase with age among elderly, making the probability of having been identified as hypertensive rises with age. Surprisingly, people that have higher educational levels were often less informed on their hypertension compared to those with an average educational level. ${ }^{13}$ Elderly ignorance to nutrition may lead to malnutrition. This ignorance may start from the childhood or due to very limited education. The importance of nutritional knowledge is based on three facts: (1) sufficient nutritional status is important for health and well-being; (2) everyone will only get enough nutrition if the food he or she eats is able to provide the nutrients needed for the optimal body growth, maintenance, and energy; and (3) nutrition science provides the necessary facts so that people can learn to use food well for nutritional improvement. ${ }^{14}$

Most elderly only consumes a small amount of vitamin C with only a small percentage has high vitamin $C$ intake (Table 1 ). This shows that the general intake of vitamin $\mathrm{C}$ subjects is inadequate for elderly aged 60 years and over. The multivariate analysis shows that there was a significant effect of vitamin C intake on high blood pressure after controlled by other factors (Table 3 ). The results of the $2 \times 24$ hours food interviews revealed an intake of vitamin C of 56.8\% less than Recommended Dietary Allowance (RDA) and the Food Frequency Questionnaire (FFQ) results presented that 125 study subjects were classified as those who frequently consume vitamin C sources, such as orange juice in 24 people ( $1 \mathrm{x} /$ week), melon in 18 people ( $1 \mathrm{x} /$ week), papaya in 30 people (1x/week), banana in 21 people $(1 \mathrm{x} /$ day), watermelon in 12 people (1x/week), tomatoes in 18 people $(1 \mathrm{x} /$ week), vegetables (cassava leaves, spinach, long beans, green

Table 3 Coefficient Regression Analysis and p Value to between Nutrition Knowledge, Vitamin C Intake, Nutritional Status and Elderly Hypertension

\begin{tabular}{lcccccc}
\hline \multicolumn{1}{c}{ Variable } & BETA & $\begin{array}{c}\text { St.Err. of } \\
\text { BETA }\end{array}$ & B & St.Err. of B & t & p Value \\
\hline Nutrition knowledge & 0.067 & 6.453 & -2.702 & 1.062 & -3.278 & 0.011 \\
Vitamin C intake $(\mathrm{mg} /$ day) & 2.834 & 6.337 & 1.042 & 0.414 & 2.633 & 0.012 \\
Nutritional status $\left(\mathrm{kg} / \mathrm{m}^{2}\right)$ & 1.625 & 3.105 & 0.486 & 0.276 & -0.260 & 0.048 \\
\hline
\end{tabular}

*p value $<0.05$ 
mustard, carrots, cabbage, white broccoli, beans, cucumbers and sprouts) in 30 people $(1 \mathrm{x} /$ day) and in 59 people (2-3x/day). This leads to inadequate vitamin $\mathrm{C}$ intake, causing higher degree of hypertension.

The results of this study are in line with the results of a previous studies stating that vitamin $\mathrm{C}$ intake is significantly associated with blood pressure $(\mathrm{p}=0.043)$, suggesting that inadequate vitamin $\mathrm{C}$ intake may lead to lipid peroxidation, increased enzyme work, and increased oxidative stress, causing blood pressure to increase. ${ }^{5}$ This is also consistent with the study stating that if a person has inadequate intake of vitamin $\mathrm{C}$, it can influence the oxidative stress, weaken the immune system and increase the blood pressure. ${ }^{7}$ The results in this study were also reinforced by a statement that adequate intake of vitamin $\mathrm{C}$ lowers systolic and diastolic blood pressure. ${ }^{6}$ This drop in blood pressure is attributed to the antioxidant properties of vitamin $\mathrm{C}$ that improves the endothelial dysfunction. ${ }^{7}$ Blood pressure depends on the cardiac output and total peripheral resistance. One of the main determinants of total peripheral resistance is blood viscosity. ${ }^{7}$

In one prospective cohort study performed on 2,596 study subjects with year 7 diet quality score and year 10 plasma ascorbic acid in the incident of hypertension, plasma ascorbic acid was seen to have a stronger correlation with diet quality score (Pearson's $r=0.29$ ) when compared to single fruit and vegetable intakes. The food groups with strongest correlations with plasma ascorbic acid were fruit $(\mathrm{r}=0.18)$ and dark green vegetables $(\mathrm{r}=0.16)$, while the correlation between plasma ascorbic acid and dietary vitamin $\mathrm{C}$ was 0.24 . Lower consumption of ascorbic acid is found to be associated with a higher risk for hypertension. ${ }^{15}$ In 242 subjects crossectionally studied by measuring blood pressure across quartiles of plasma ascorbic acid at the 10th annual visit, a similar effect is seen in the form of changes in systolic blood pressure, $p=0,005$. This study suggested that vitamin $\mathrm{C}$ may be an important factor in blood pressure regulation. ${ }^{16}$

Vitamin C works as an antioxidant by way of donating hydrogen from its hydroxyl group to superoxide radicals, making them harmless radicals. ${ }^{5}$ Antioxidant in vitamin $\mathrm{C}$ is able to eliminate free radical compounds in cells in the presence of ascorbate peroxidase (APX), which is found in the form of isoenzymes in vitamin $\mathrm{C}$ and which plays an important role in inhibiting oxidation in the body by acting as an inhibitor. ${ }^{6}$ In the mitochondria, oxidants are reduced through the NADPH oxidase process into an intermediate needed for enzyme reactions (xanthine oxidase) and endogenous antioxidant support in the form of superoxide dismutase (SOD).

The superoxide dismutase antioxidants convert superoxide radicals into hydrogen peroxidase. The most efficient hydrogen peroxidase is prevented by GPx enzymes that require GSH as an electron donor. GSH oxidase is then converted back into GSH with the help of glutathione reductase enzyme that converts NADPH as its electron donor. Some metals (Fe2 +, CU + and others) may suffer from hydroperoxidase damage due to hydroxyl radicals. ${ }^{8}$ Hydroxyl radicals obtain electrons from polyunsaturated fatty acids that can form lipid radicals. Lipid radicals may become peroxyl radicals when they interact with oxygen. In addition, radical peroxyl, if it is not reduced by antioxidants, will become lipid peroxidase, which may trigger oxidative stress.

Most elderly subjects in the current study had normal nutritional status and only a small percentage experienced obesity (Table 1). This shows that the nutritional status of the subjects of the study is generally normal. Multivariate analysis have shown that nutritional status significantly influence the blood pressure (Table 3).

Obesity seems to have an active influence on hypertension with obesity nutritional status is found to be 4.57 times higher (95\% CI: 1.497-13.958) in hypertensive patients compared to those who are thin and have normal body weight after other factors are controlled. ${ }^{17}$ Prevalence of overweight is associated with obesity and cardiovascular diseases. Meanwhile, BMI is highly correlated with body weight and has proximity to the body energy stores, without the ability to predict the distribution of fat. ${ }^{18}$

Previous studies have found a significant relationship between the nutritional status and socio economic status. Elderly with low socioeconomic status is shorter and thinner than the those with moderate and high economic status. ${ }^{6}$ The same study also stated that there is a significant relationship between obesity and hypertension where individuals with obesity have 2.41 times higher risk to suffer from hypertension than individuals who are not obese. ${ }^{19}$ Nutritional status significantly correlates with blood pressure after age, sex, smoking status, sodium intake, and potassium intake factors are controlled. Elderly with mobility impairments have lower performance 
in the ability to perform activities of daily living and greater dependence on care, including for getting meals and purchasing food. ${ }^{20}$

It is concluded that the majority of subjects in this study have good nutrition knowledge, low vitamin $C$ intake, and normal nutritional status based on BMI. Elderly with hypertension may associate with female sex, older age, lower vitamin $\mathrm{C}$ intake, lower BMI, and lower educational level.

\section{References}

1. Ministry of Health of the Republic of Indonesia. Gambaran kesehatan lanjut usia di Indonesia. $1^{\text {st }}$ ed. Jakarta: Buletin Jendela Data dan Informasi Kesehatan; 2013.

2. Paul MC, Barrett B, Daichi S. Systolic blood pressure goals to reduce cardiovascular disease among older adults. Am J Med Sci. 2014;348(2):129-134.

3. Ding M, Huang T, Bergholdt HK, Nordestgaard BG, Ellervik C, Qi L, et al. Dairy consumption, systolic blood pressure, and risk of hypertension: mendelian randomization study. BMJ. [serial on the internet]. 2017 Mar [cited 2017 Apr 20];356(1000):[about 10p.]. Available from: http://www.bmj.com/ content/356/bmj.j1000.long.

4. Anthony JV, Lauren WC. Madeline M, Philip DS. High blood pressure knowledge among primary care patients with known hypertension: a North Carolina Family Medicine Research Network (NC-FM-RN) study. J Am Board Fam Med. 2008;21(4):300-8.

5. Chen ST, Maruthur NM, Appel LJ. The effect of dietary patterns on estimated coronary heart disease risk results from the Dietary Approaches to Stop Hypertension (DASH) trial. Circ Cardiovasc Qual Outcomes. 2010; 3(5):484-9.

6. Costa BVL, Fonseca LM, Lopes ACS. Nutritional status and associated factors in institutionalized elderly. J Nutr Disorders Ther. 2012; 2(3):1-5.

7. Yokoyama Y, Nishimura K, Barnard ND, Takegami M, Watanabe M, Sekikawa A, et al. Vegetarian diets and blood pressure: metaanalysis. JAMA Intern Med. 2014;174(4):57787.

8. Stephen PJ, Eliseo G, Lawrence JA, Edgar RM. Meta-analysis of vitamin C and blood pressure. Am J Clin Nutr. 2012;95(5):1079-88.

9. Utsugi MT, Ohkubo T, Kikuya M, Kurimoto A, Sato RI, Suzuki K, et al. Fruit consumption and risk of home hypertension. Hypertens Res. 2008; 31(7):1435-43.

10. Anthony JV, Lauren WC, Philip DS. Blood

pressure knowledge among hypertensive patients. J Am Board Fam Med. 2008; 21(4):300-8

11. Ina Q, Marie DT, Jes SL, Hans I, Jeroen MLH, Lars F, et al. Self-reported knowledge and awareness about blood pressure and hypertension: a cross-sectional study of a random sample of men and women aged 60-74 years. Clin Epidemiol. 2014;6(3):81-7.

12. Asgedom SW, Gudina EK, Desse TA. Assessment of blood pressure control among hypertensive patients in Southwest Ethiopia. PLoS One. 2016;1(11):1-12.

13. Macia E, Duboz P, Gueye L. Prevalence, awareness, treatment and control of hypertension among adults 50 years and older in Dakar, Senegal. Cardiovasc J Afr. 2012; 23(5):265-9.

14. Ijarotimi OS, Keshinro 00. Nutritional knowledge, nutrients intake and nutritional status of hypertensive patients in Ondo State, Nigeria. Tanzan J Health Res. 2008; 10(2): 5967

15. Buijsse B, Jacobs DRJ, Steffen LM, Kromhout D, Gross MD. Plasma ascorbic acid, a priori diet quality score, and incident hypertension: a prospective cohort study. PLoS ONE. 2015; 10(12):1-13.

16. Gladys B, Christopher DJ, Edward PN, Mark H, Patricia BC. Vitamin C in plasma is inversely related to blood pressure and change in blood pressure during the previous year in young black and white women. Nutr J. 2008;7(35):19.

17. Macia E, Gueye L, Duboz P. Hypertension and obesity in Dakar, Senegal. PLoS ONE. 2016; 11(9):1-14.

18. Wilbert SA. Association of obesity with hypertension. Ann Transl Med. 2017;5(17):350.

19. Wang SK, Ma W, Wang S, Yi XR, Jia HY, Xue F, et al. Obesity and its relationship with hypertension among adults 50 years and older in Jinan, China. PLoS ONE. 2014;9(12):1-10.

20. Maeve R, Phyo K, Heiko M, Anne M, Pooler R, 
Archbold, Helene MN, Chris CP, et al. Nature or nurture; $\mathrm{BMI}$ and blood pressure at 90 . Indings from the Belfast Elderly Longitudinal Free- living Aging Study (BELFAST). Age (Dordr). 2009;31(4):261-7. 